\section{Case Reports in Gastroenterology}

Case Rep Gastroenterol 2017;11:462-472

DOI: $10.1159 / 000475747$

Published online: August 17, 2017 (c) 2017 The Author(s)

Published by S. Karger AG, Basel www.karger.com/crg

This article is licensed under the Creative Commons Attribution-NonCommercial 4.0 International License (CC BY-NC) (http://www.karger.com/Services/OpenAccessLicense) Usage and distribution for commercial purposes requires written permission.

\title{
Non-Meckel Small Intestine Diverticulitis
}

\author{
Shamim Ejaz ${ }^{\mathrm{a}}$ Raghu Vikram ${ }^{\mathrm{b}} \quad$ John R. Stroehlein ${ }^{\mathrm{a}}$ \\ a Department of Gastroenterology, Hepatology, and Nutrition, The University of Texas \\ MD Anderson Cancer Center, Houston, TX, USA; ${ }^{b}$ Department of Diagnostic Radiology, \\ The University of Texas MD Anderson Cancer Center, Houston, TX, USA
}

\section{Keywords}

Small intestine · Diverticulitis · Management

\begin{abstract}
Non-Meckel small intestine diverticulitis can have many manifestations and its management is not well-defined. We report 4 unselect cases of small intestine diverticulitis; all patients were seen by the same physician at the Emergency Center at The University of Texas MD Anderson Cancer Center between 1999 and 2014. The median age at diagnosis of these patients was 82 years (range, 76-87 years). All 4 patients presented with acute onset of abdominal pain, and computed tomography scans showed characteristics of small intestine diverticulitis unrelated to cancer. Most of the diverticula were found in the region of the duodenum and jejuno-ileal segments of the small intestine. The patients, even those with peripancreatic inflammation and localized perforation, were treated conservatively. Non-Meckel diverticulitis can be overlooked in the initial diagnosis because of the location of the diverticulosis, the age of the patient, and the rarity of the disease. Because patients with non-Meckel small intestine diverticulitis can present with acute abdominal pain, non-Meckel small intestine diverticulitis should be considered in the differential diagnosis of patients with acute abdominal pain, and computed tomography scans can help identify the condition. Because of the rarity of non-Meckel small intestine diverticulitis, few studies have been published, and the data are inconclusive about how best to approach these patients. Our experience with
\end{abstract}




\section{Case Reports in \\ Gastroenterology}

Case Rep Gastroenterol 2017;11:462-472

DOI: $10.1159 / 000475747$

(C) 2017 The Author(s). Published by S. Karger AG, Basel www.karger.com/crg

Ejaz et al: Non-Meckel Small Intestine Diverticulitis

these 4 elderly patients indicates that non-Meckel small intestine diverticulitis can be treated conservatively, which avoids the potential morbidity and mortality of a surgical approach.

(C) 2017 The Author(s)

Published by S. Karger AG, Basel

\section{Introduction}

Non-Meckel small intestine diverticular disease is rare and has been reported in 0.3$1.3 \%$ of postmortem studies [1] and in $0.5-1.9 \%$ of cases in small intestine contrast media studies [2]. Duodenum is the most common site of small bowel diverticula seen in up to $6 \%$ of patients. Diverticula in the jejunum and ileum are much less common. The reported incidence of diverticula in the jejuno-ileum is $0.07-1.0 \%$ on imaging studies and $0.2-20$ and $0.07-0.8 \%$ on autopsies, respectively $[3,4]$. Jejunal diverticulosis ranges from 0.26 to $1.3 \%$ of cases found on autopsy and from 0.075 to $8 \%$ on imaging [4]. However, most of the data are from almost 40 years ago, when imaging was not done on a regular basis; therefore, the reported incidence may be lower than the actual incidence reported.

Non-Meckel diverticulitis can be overlooked in the initial diagnosis because of the location of the diverticulosis, the age of the patient, and the rarity of the disease. Patients with non-Meckel small intestine diverticulosis may be asymptomatic; however, these patients can also present with malabsorption, complete small intestine obstruction, bleeding, and diverticulitis. Patients with non-Meckel small intestine diverticulitis can also present with acute abdominal pain, so non-Meckel diverticulitis should be considered in the differential diagnosis of patients with this symptom, and computed tomography (CT) scans can help identify the disease. Because most patients with non-Meckel small intestine diverticulitis are in their seventh decade of life and have several comorbidities, whether to treat these patients conservatively or surgically has been controversial. Owing to the rarity of non-Meckel small intestine diverticulitis, few studies have been published, and the data are inconclusive about how best to approach these patients.

Non-Meckel diverticula are not true diverticula, as they mostly consist of mucosa, submucosa, and serosa, whereas Meckel diverticula contain muscular wall in addition to mucosa, submucosa, and serosa. Non-Meckel diverticula are thin walled and fragile and are usually found along the mesenteric border of small intestine. Two theories have been proposed to explain the pathogenesis of non-Meckel small intestine diverticula. Cocks and Zeno [5] suggested that non-Meckel diverticula form when structural weakness occurs where the vasa recta blood vessels and nerves penetrate the mesentery area; this area has less fat and less longitudinal muscle than other areas [6-8]. Others believe that non-Meckel small intestine diverticula result from ineffective and abnormal contractions of an underlying motility disorder.

We present 4 elderly patients with non-Meckel small intestine diverticulitis who were seen by the same physician at the Emergency Center at The University of Texas MD Anderson Cancer Center between 1999 and 2014. All 4 patients were treated conservatively and were followed actively. Our findings support a conservative approach for treating elderly patients with small intestine diverticulitis, and we suggest that surgery should only be considered for complicated cases. Whereas previous studies have focused on all aspects of small 


\section{Case Reports in \\ Gastroenterology} \begin{tabular}{l|l} 
Case Rep Gastroenterol 2017;11:462-472 \\
\begin{tabular}{l|l}
\hline DOI: $10.1159 / 000475747$ & $\begin{array}{l}\text { ( ) 2017 The Author(s). Published by S. Karger AG, Basel } \\
\text { www.karger.com/crg }\end{array}$
\end{tabular} \\
\hline
\end{tabular}

Ejaz et al.: Non-Meckel Small Intestine Diverticulitis

intestine diverticulosis in patients of varying ages, we have limited our series to elderly patients with non-Meckel small intestine diverticulitis.

\section{Case Reports}

\section{Case 1}

An 87-year-old man presented to the MD Anderson Emergency Center with acute abdominal pain and fever of $38^{\circ} \mathrm{C}$, but he did not have nausea, vomiting, or chills. Marked abdominal tenderness was noted along the left lower quadrant of the abdomen. Sounds in the intestine were noted, and there was no sign of any lesion or organ enlargement. The physical examination also revealed an inguinal hernia, which was completely reducible without any tenderness. The patient's white blood cell count was $13.8 \mathrm{~K} / \mu \mathrm{L}$ (normal range, $4-11 \mathrm{~K} / \mu \mathrm{L}$ ), and his serum glucose level was $144 \mathrm{mg} / \mathrm{dL}$ (normal range, $70-110 \mathrm{mg} / \mathrm{dL}$ ).

An abdominal radiograph showed a nonspecific bowel gas pattern in the colon and small intestine without evidence of obstruction. The contrast-enhanced CT scan performed showed multiple diverticula along the mesenteric border predominantly distributed in jejunum. There was mesenteric fat stranding, circumferential thickening of a small segment of small bowel, and a small pocket of extraluminal gas adjacent to a jejunal diverticulum (Fig. $1 \mathrm{a}, \mathrm{b})$ suggesting small intestine diverticulitis with contained perforation.

Following consultation with a surgical consultant and discussion with family members, it was decided to observe the patient with serial examinations and clinical assessment. The patient was given intravenous fluids, nothing by mouth, and intravenous piperacillin and tazobactam ( $3.75 \mathrm{~g}$, every $8 \mathrm{~h}$ ). The patient's pain improved, his white blood cell count returned to baseline within $24 \mathrm{~h}$, and his temperature normalized. The patient was discharged from the hospital after 5 days. He was given levofloxacin $(500 \mathrm{mg}$, once a day) orally for 5 days with instructions to follow-up in the clinic. He has had regular follow-up visits every 6 months for 5 years and has not shown any recurrence of small intestine diverticulitis.

\section{Case 2}

An 86-year-old woman presented to the MD Anderson Emergency Center with moderately severe abdominal pain (severity, 8-10). Nausea and vomiting started 5 days before the onset of pain. The pain had become very severe within the prior $24 \mathrm{~h}$. She had a history of similar symptoms, which resulted in a cholecystectomy and pancreatitis.

During the physical examination, the physician found a mid-abdominal mass, which did not move with respiration and had features that were suspicious for inflammatory process. The patient's white blood cell count was $11.4 \mathrm{~K} / \mu \mathrm{L}$ (normal range, $4-11 \mathrm{~K} / \mu \mathrm{L}$ ). The CT scan (Fig. 2a, b) showed an inflammatory mass adjacent to the second portion of the duodenum within the mesentery, but the pancreatic head and remaining pancreas appeared intact. Endoscopy findings showed 2 large diverticula in the second portion of the duodenum without evidence of overt perforation.

Because the patient was allergic to tetracycline and ciprofloxacin, she was treated with oral metronidazole (500 mg, 3 times daily) and trimethoprim with sulfamethoxazole (160 and $800 \mathrm{mg}$, respectively, twice daily) for 2 weeks. Surgical consult was obtained, and the physician decided to treat the patient conservatively because the patient's symptoms re- 
Ejaz et al.: Non-Meckel Small Intestine Diverticulitis

solved relatively quickly and because the patient had no sign of free perforation on imaging. The patient was followed up in the clinic and was placed on long-term doxycycline (100 mg) twice daily for 1 week followed by no treatment for 5-6 weeks for approximately 1 year to treat bacterial overgrowth.

\section{Case 3}

A 78-year-old woman presented to the MD Anderson Emergency Center with abdominal pain and diarrhea that had persisted for 5 days. The patient reported no other systemic problems, nausea, or vomiting. She had a history of hypertension, hyperlipidemia, atrial fibrillation, and diabetes. She also had a remote history of extraskeletal osteosarcoma of the thigh with lung metastasis, which had been treated with cytotoxic chemotherapy, lung resection, and radiation.

At the time of her presentation to MD Anderson her blood work revealed normal values, except for an elevated white blood cell count $(16.4 \mathrm{~K} / \mu \mathrm{L}$; normal range, $4-11 \mathrm{~K} / \mu \mathrm{L})$. The urinalysis results of over 100 white blood cells per high-power field (normal range, 0-2) were consistent with large leukocyte esterase. The total bilirubin level was also slightly elevated $(2.1 \mathrm{mg} / \mathrm{dL}$; normal range, $0.0-1.0 \mathrm{mg} / \mathrm{dL})$. The patient was treated with oral levofloxacin $(500 \mathrm{mg}$, once per day) because she was thought to have a urinary tract infection, but she continued to have vague abdominal pain.

She underwent abdominal and pelvic CT studies, which showed multiple diverticula in the small intestine that were consistent with small intestine diverticulitis, with a large diverticulum $(4.7 \mathrm{~cm})$ near the jejunum (Fig. 3). There were no signs of perforation. Because of her age and other comorbidities, the patient was treated conservatively and was discharged from the hospital. She was treated with oral levofloxacin (500 mg, once per day) for 5 days; her leukocyte count normalized, and subsequent abdominal examinations revealed no signs of tenderness.

She remained asymptomatic for 1 year and then presented to the MD Anderson Emergency Center with unrelated transient small intestine obstruction. A CT scan showed mildly dilated, fluid-filled loops of the small intestine, consistent with possible early partial obstruction; however, the patient's condition improved with oral restriction and intravenous fluids. The patient never had any episodes of recurrence of small intestine diverticulitis during 7 years of follow-up, although she reported diarrhea on and off until her last follow-up. The diarrhea was attributed to diabetes-related autonomic dysfunction, and no other causes of chronic diarrhea were found.

Seven years after her small intestine diverticulitis diagnosis, the patient developed esophageal adenocarcinoma, which was limited to the esophagus. Because of her advanced age and poor social support, the patient refused treatment and died at the age of 85 years.

\section{Case 4}

A 76-year-old man presented to the MD Anderson Emergency Center with constipation and a 2-day history of postprandial abdominal pain. His abdominal pain was initially transient but increased in intensity and was associated with nausea and vomiting but no fever. Two years before this episode of abdominal pain, the patient had adenocarcinoma of the hepatic flexure of the colon, which was treated with right hemicolectomy, without any evi- 
Ejaz et al.: Non-Meckel Small Intestine Diverticulitis

dence of recurrence. The pain was initially thought to be an intestinal obstruction owing to adhesions caused by the hemicolectomy.

The patient's blood tests revealed an elevated white blood cell count $(19.9 \mathrm{~K} / \mu \mathrm{L}$; normal range, 4-11 K/ $\mu \mathrm{L}$ ) and elevated serum levels of amylase (136 U/L; normal range, 30-110 $\mathrm{U} / \mathrm{L}$ ) and lipase (823 U/L; normal range, 23-300 U/L). An abdominal X-ray showed prominent small intestine loops with multiple air-fluid levels, suggestive of early small intestine obstruction. CT scans of the abdomen with and without contrast showed an inflammatory process in the proximal jejunum. Small amounts of localized luminal air were observed, and there were inflammatory changes in the adjacent fat. The CT study of the abdomen showed numerous small intestine diverticula near the jejunum (Fig. 4).

Surgical opinion was obtained, but surgery was deferred for conservative management. The patient was put on a diet of clear liquids and intravenous hydration and was given intravenous ciprofloxacin (500 mg, twice per day) and metronidazole (500 mg, 3 times per day). The patient's condition improved, and he was discharged from the hospital after 2 days and was sent home with oral antibiotics of ciprofloxacin (500 mg, twice per day) and metronidazole (500 mg, 3 times per day) for another 12 days, with instructions to follow-up in the gastroenterology clinic. He recovered well, and, almost 8 months after his initial symptoms, he has had no abdominal pain or obstruction recurrence.

\section{Discussion}

We present 4 patients with symptomatic non-Meckel small intestine diverticulitis. In our case series, the median age at diagnosis of the 4 patients was 82 years (range, 76-87 years). They all had the typical clinical presentation of small intestine diverticulitis, including abdominal pain and leukocytosis, and 2 patients also presented with elevated amylase and lipase levels (Table 1). All patients were diagnosed on the basis of CT findings. Patient 2 also underwent esophagogastroduodenoscopy and endoscopic ultrasonography, which revealed a diverticulum in the duodenum, whereas the other 3 patients had diverticulum in the jejunum. All 4 patients were treated conservatively (without surgery), and none of the patients experienced disease recurrence. The median follow-up was 3.5 years (range, 1-7 years).

In a series of 208 patients which Akhrass et al. [9] collected over a 23-year period, 79\% of the diverticula were found in the duodenum, $18 \%$ in the jejunum or ileum, and only $3 \%$ were found in all 3 segments. Only 42 patients presented with complications, of which only 2 patients were reported to have small intestine diverticulitis with perforations and abscess [9]. Others reported acute complications in 20 patients out of 112 cases collected over a period of 15 years, and only 1 had small intestine diverticulitis [10]. Kouraklis et al. [11] reported only 7 cases of small intestine diverticulitis out of 77 patients in almost 30 years of data. In a similar series, only 5 patients had jejunal diverticula and 2 had ileal diverticula [12]. Palder and Frey [13] reported 3 out of 47 patients with small intestine diverticulitis. Songne et al. [14] reported 3 cases of small intestine diverticulitis in a retrospective review period extending from 1995 to 2001.

Patients with small intestine diverticulitis frequently present with acute abdominal pain, leukocytosis, and elevated amylase levels, which is very similar to the presentation of 
Ejaz et al.: Non-Meckel Small Intestine Diverticulitis

our patients. Only 6-20\% of patients with small intestine diverticulosis present with complications such as obstruction, malabsorption, hemorrhage, diverticulitis, or perforations. Duodenal diverticula are common but rarely cause severe diverticulitis that requires resection [2], whereas up to $15 \%$ of patients with jejunal diverticulosis may require small intestine resection for complications such as perforation and diverticulitis [4]. Compared with patients with jejunal diverticula, patients with jejuno-ileal diverticula are 4 times more likely to develop complications such as obstruction and diverticulitis and are nearly 18 times more likely to experience perforation and abscess if diagnosis is delayed [9]. Although some studies [9, 15-17] favor surgical intervention, patients with local and self-limited inflammation and without free perforation can be treated conservatively, and this may be the best approach. However, surgery may be necessary for patients with acute abdominal pain [14]. Conservative management of small intestine diverticulitis may include treatment with parenteral antibiotics and hydration, which worked well for our 4 elderly patients.

\section{Conclusion}

Small bowel diverticulitis other than non-Meckel can present as acute abdominal pain and should always be considered in the differential diagnosis of acute abdominal findings on examination or cross-sectional imaging. Our results indicate that small bowel non-Meckel diverticulitis can be managed conservatively.

\section{Statement of Ethics}

There are no ethical conflicts to declare. Informed consent has also been obtained from the involved patient, and all procedures and data are gathered as per IRB-approved protocol (PA14-1057) guidelines.

\section{Disclosure Statement}

The authors do not have any potential conflicts of interest to disclose.

\section{Author Contributions}

All authors contributed equally to the paper. 


\section{Case Reports in Gastroenterology}

\begin{tabular}{l|l}
\hline Case Rep Gastroenterol 2017;11:462-472 \\
\hline DOI: 10.1159/000475747 & $\begin{array}{l}\text { (c) } 2017 \text { The Author(s). Published by S. Karger AG, Basel } \\
\text { www.karger.com/crg }\end{array}$ \\
\hline
\end{tabular}

Ejaz et al.: Non-Meckel Small Intestine Diverticulitis

\section{References}

-1 Fisher JK, Fortin D: Partial small bowel obstruction secondary to ileal diverticulitis. Radiology 1977;122: 321-322.

2 Cattell RB, Mudge TJ: The surgical significance of duodenal diverticula. N Engl J Med 1952;246:317324.

-3 Miller RE, McCabe RE, Salomon PF, Knox WG: Surgical complications of small bowel diverticula exclusive of Meckel's. Ann Surg 1970;171:202-210.

-4 Cunningham SC, Gannon CJ, Napolitano LM: Small-bowel diverticulosis. Am J Surg 2005;190:37-38.

5 Cocks JR, Zino FJ: Acute diverticulitis of the terminal ileum. Br J Surg 1968;55:45-49.

6 Afridi SA, Fichtenbaum CJ, Taubin H: Review of duodenal diverticula. Am J Gastroenterol 1991;86:935938.

7 Edwards HC: Intestinal diverticulosis and diverticulitis. Ann R Coll Surg Engl 1954;14:371-388.

8 Edwards HC: Diverticulosis and diverticulitis of the intestine. Postgrad Med J 1953;29:20-27.

-9 Akhrass R, Yaffe MB, Fischer C, Ponsky J, Shuck JM: Small-bowel diverticulosis: perceptions and reality. J Am Coll Surg 1997;184:383-388.

-10 Tsiotos GG, Farnell MB, Ilstrup DM: Nonmeckelian jejunal or ileal diverticulosis: an analysis of 112 cases. Surgery 1994;116:726-731; discussion 731-722.

11 Kouraklis G, et al: Clinical implications of small bowel diverticula. Isr Med Assoc J 2002;4:431-433.

12 Mantas D, Kykalos S, Patsouras D, Kouraklis G: Small intestine diverticula: is there anything new? World J Gastrointest Surg 2011;3:49-53.

13 Palder SB, Frey CB: Jejunal diverticulosis. Arch Surg 1988;123:889-894.

14 Songne B, Costaglioli B, Michot F, Teniere P, Scotte M: Management of surgical complications of smallbowel diverticulosis. Gastroenterol Clin Biol 2005;29:415-418.

15 Gliustra PE, Killoran PJ, Root JA, Ward WW: Jejunal diverticulitis. Radiology 1977;125:609-611.

16 Martin WL, Grotzinger PJ, Bower R: Jejunal diverticula. AMA Arch Surg 1954;69:711-717.

17 Zeifer HD, Goersch H: Duodenal diverticulitis with perforation. Arch Surg 1961;82:746-754.
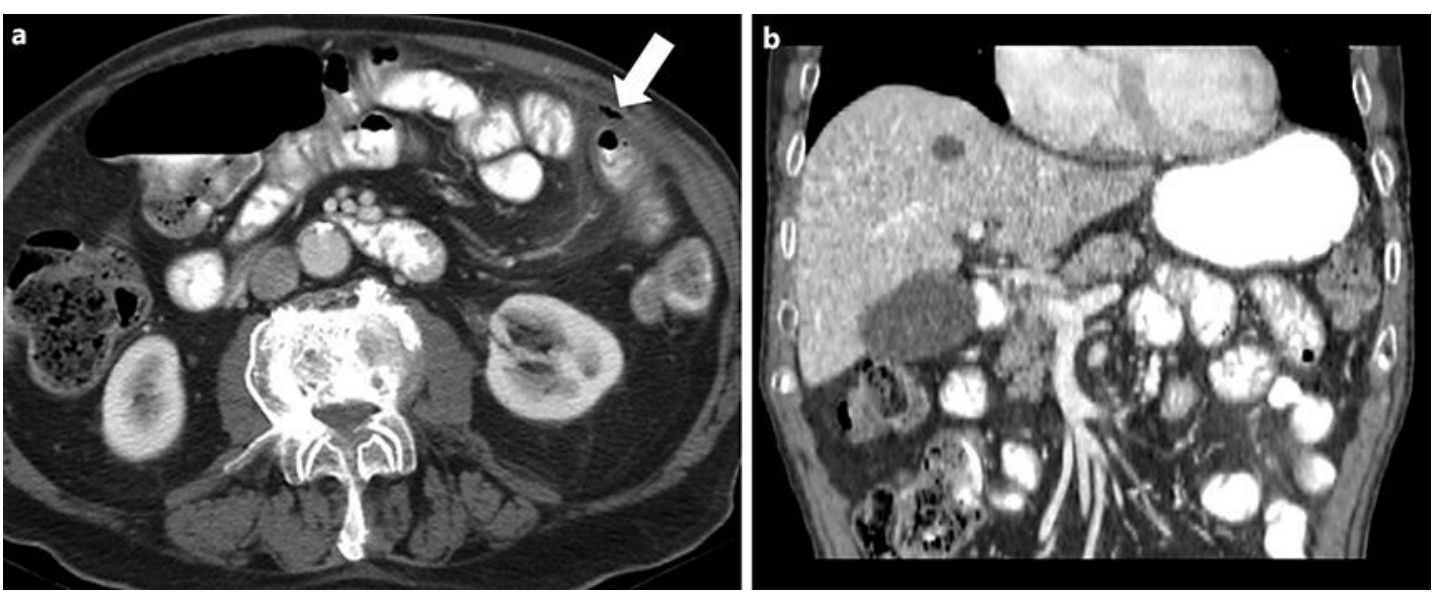

Fig. 1. a Axial CT scan of the abdomen with intravenous and gastrointestinal-positive contrast. A small pocket of gas in the extraluminal location is noted indicating localized perforation. There is also very mesenteric fat-finding associated with inflammation related to small bowel diverticulitis. b Coronal reconstructions of the contrast-enhanced CT scan of the same patient shows her jejunal diverticulum arising from the mesenteric border. 


\section{Case Reports in Gastroenterology}

Case Rep Gastroenterol 2017;11:462-472
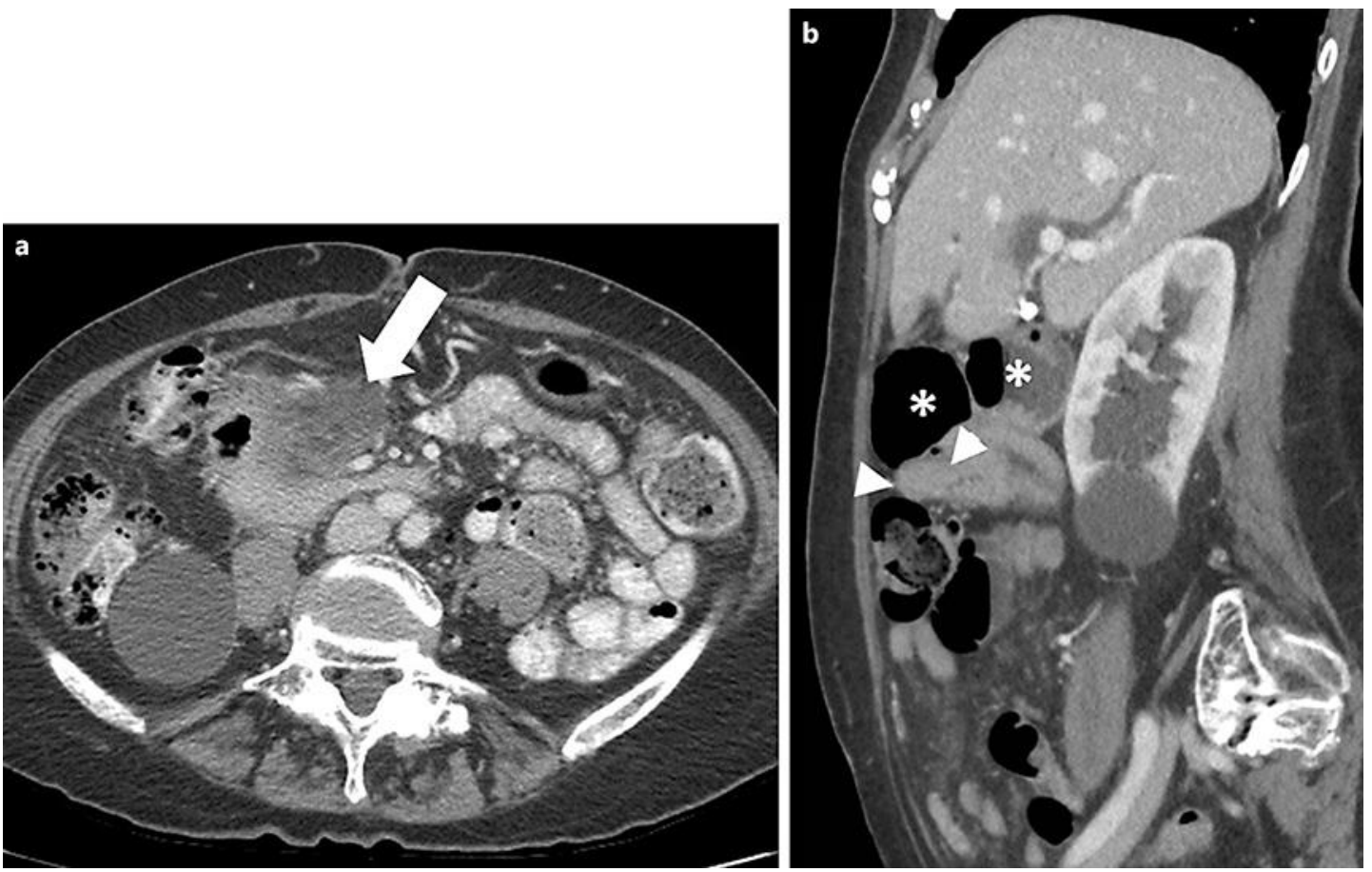

Fig. 2. a Axial CT scan of the abdomen with intravenous and gastrointestinal-positive contrast. There is fat stranding and an inflammatory mass in the root of the small bowel mesentery (arrow). b Sagittal reconstructions of the CT scan of the abdomen in the same patient shows 2 giant diverticula (asterisk) arising from the second part of the duodenum (arrowheads). 


\section{Case Reports in Gastroenterology}

www.karger.com/crg

Ejaz et al.: Non-Meckel Small Intestine Diverticulitis

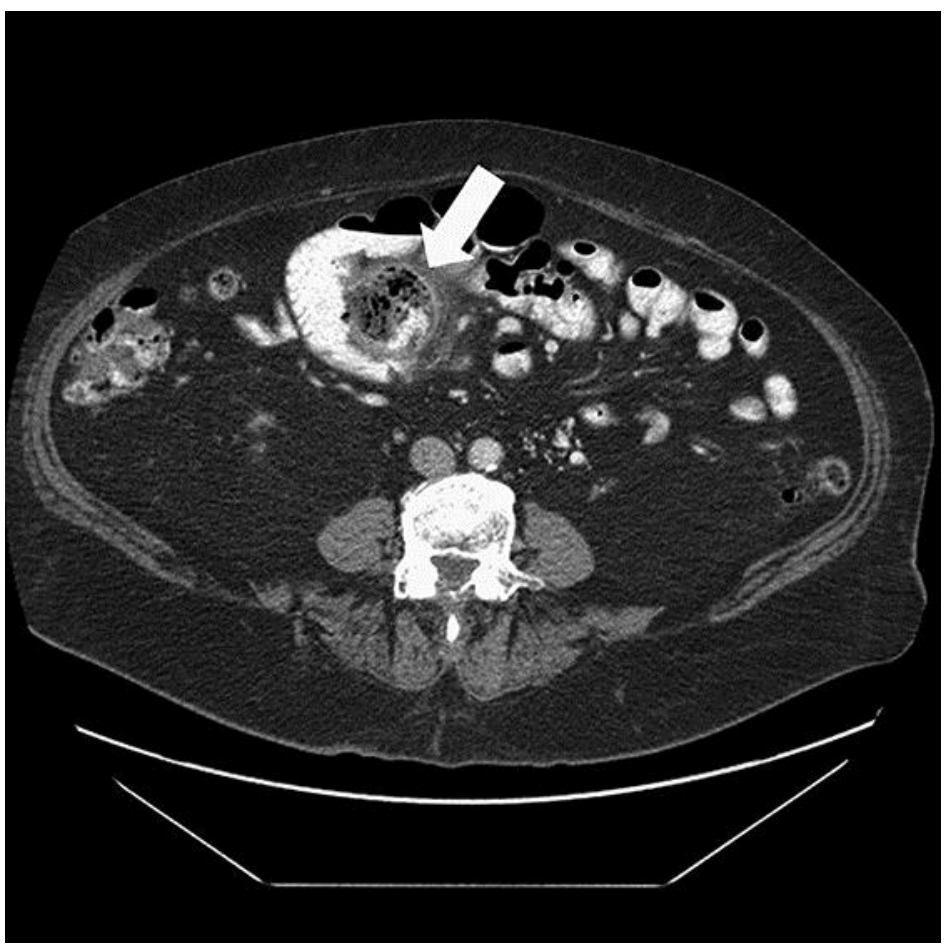

Fig. 3. Axial contrast-enhanced CT scan of the abdomen. A larger diverticulum arising from the mesenteric border of the jejunum is noted with surrounding inflammatory fat stranding (arrow). 


\begin{tabular}{|c|c|c|}
\hline \multirow{3}{*}{$\begin{array}{r}\text { Case Reports in } \\
\text { Gastroenterology }\end{array}$} & \multirow{2}{*}{\multicolumn{2}{|c|}{ Case Rep Gastroenterol 2017;11:462-472 }} \\
\hline & & \\
\hline & DOI: $10.1159 / 000475747$ & $\begin{array}{l}\text { (c) } 2017 \text { The Author(s). Published by S. Karger AG, Basel } \\
\text { www.karger.com/crg }\end{array}$ \\
\hline
\end{tabular}

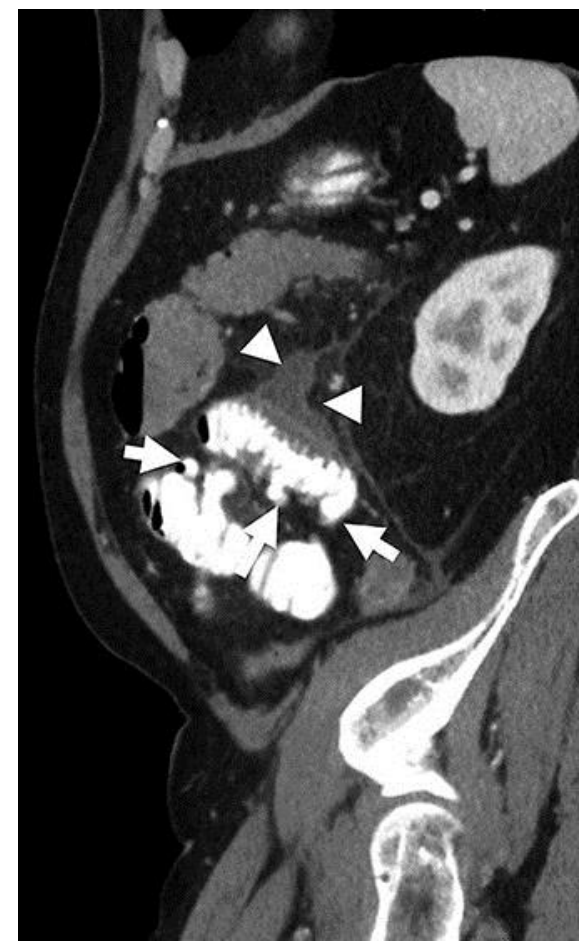

Fig. 4. Sagittal reconstructions of contrast-enhanced CT scan performed with gastrointestinal contrast. There are multiple small ball diverticula (arrows) with inflammatory changes extending along the mesentery (arrowhead). 
Ejaz et al.: Non-Meckel Small Intestine Diverticulitis

Table 1. Non-Meckel small intestine diverticulitis in 4 patients treated between 1999 and 2014

\begin{tabular}{|c|c|c|c|c|}
\hline Characteristic & Patient 1 & Patient 2 & Patient 3 & Patient 4 \\
\hline $\begin{array}{l}\text { Age at diagnosis, } \\
\text { years }\end{array}$ & 87 & 86 & 78 & 76 \\
\hline Sex & M & $\mathrm{F}$ & $\mathrm{F}$ & M \\
\hline Symptoms & Abdominal pain & Abdominal pain & $\begin{array}{l}\text { Abdominal pain } \\
\text { and diarrhea }\end{array}$ & $\begin{array}{l}\text { Abdominal pain } \\
\text { (generalized) }\end{array}$ \\
\hline $\begin{array}{l}\text { Laboratory } \\
\text { values }\end{array}$ & $\begin{array}{l}\text { Elevated leucocytes } \\
\text { and localized } \\
\text { perforation }\end{array}$ & $\begin{array}{l}\text { Elevated leucocytes } \\
\text { and amylase due to } \\
\text { peripancreatic } \\
\text { involvement }\end{array}$ & $\begin{array}{l}\text { Elevated } \\
\text { leucocytes }\end{array}$ & $\begin{array}{l}\text { Elevated leukocytes, } \\
\text { amylase and lipase }\end{array}$ \\
\hline $\begin{array}{l}\text { Methods of } \\
\text { diagnosis }\end{array}$ & CT abdomen & $\begin{array}{l}\text { EGD with EUS/and } \\
\text { CT }\end{array}$ & CT abdomen & CT abdomen \\
\hline $\begin{array}{l}\text { Anatomic } \\
\text { region }\end{array}$ & Jejunum & Duodenum & $\begin{array}{l}\text { Multiple/one near } \\
\text { jejunum }\end{array}$ & Jejunum \\
\hline $\begin{array}{l}\text { Other } \\
\text { treatment }\end{array}$ & Conservative & $\begin{array}{l}\text { Conservative with } \\
\text { long term antibiotic }\end{array}$ & Conservative & Conservative \\
\hline $\begin{array}{l}\text { Status/ } \\
\text { follow-up }\end{array}$ & $\begin{array}{l}\text { Dead/5-year } \\
\text { follow-up }\end{array}$ & $\begin{array}{l}\text { Alive/2-year } \\
\text { follow-up }\end{array}$ & $\begin{array}{l}\text { Dead/7-year } \\
\text { follow-up }\end{array}$ & $\begin{array}{l}\text { Alive/1-year } \\
\text { follow-up }\end{array}$ \\
\hline
\end{tabular}

None of the patients had surgery/segment resection or recurrence. CT, computed tomography; EGD, esophagogastroduodenoscopy; EUS, endoscopic ultrasonography. 